\title{
Intrageneric Relationships of the Actinomycete Genus Micromonospora
}

\author{
CATHRIN KOCH, REINER M. KROPPENSTEDT, AND ERKO STACKEBRANDT* \\ DSMZ-German Collection of Microorganisms and Cell Cultures GmbH, \\ 38124 Braunschweig, Germany
}

\begin{abstract}
The intrageneric structure of the genus Micromonospora was determined by analyzing the 16S ribosomal DNAs of the type strains of all but one of the 15 validly described species and four subspecies and 19 other Micromonospora strains, most of which represented invalidly described species. One of the 19 other Micromonospora strains grouped outside a phylogenetically tight genus Micromonospora, which appeared to be closely related to other genera belonging to the family Micromonosporaceae. The level of sequence similarity for the $16 \mathrm{~S}$ ribosomal DNAs of most of the type strains was $98 \%$. Values in the same range were also found when the sequences of the type strains and most of the other Micromonospora strains were compared. Whether the invalidly described species actually represent taxa that are worthy of species status should be investigated by performing DNA reassociation studies and thoroughly comparing physiological and chemotaxonomic properties.
\end{abstract}

The genus Micromonospora Ørskov 1923 (12) is the type genus of the family Micromonosporaceae Krasil'nikov 1938 (9), emend. Goodfellow, Stanton, Simpson, and Minnikin 1990 (6). This family now contains several genera, including the genera Micromonospora, Actinoplanes, Dactylosporangium, and Pilimelia, which are morphologically distinct but chemotaxonomically similar (6). Recently, workers have described two new genera, the genus Catenuloplanes (22) and the genus Couchioplanes (19), which can also be assigned to this family on the basis of their phylogenetic positions. The inclusion of these genera increases the phenotypic and chemotaxonomic heterogeneity of the family Micromonosporaceae (22). Phylogenetically, this family forms one of the major sublines within the order Actinomycetales $(4,16,19)$; however, with the exception of Couchioplanes strains (19), very few representatives of each genus have been included in $16 \mathrm{~S}$ rRNA cataloging studies (17), analyses of 16S rRNA by the reverse transcriptase method (19), or analyses of $16 \mathrm{~S}$ ribosomal DNA (rDNA) by the PCR method (19). Of the 15 validly described Micromonospora species, only a single strain of Micromonospora chalcea (strain NRRL B-2344) was included in a phylogenetic analysis in which partial 16S RNA sequences were used (16) (the Approved Lists of Bacterial Names [14a] includes 12 species, and three species were validly described after 1980; however, according to Kawamoto [8] no type strain of Micromonospora gallica is available). In order to provide a basis for determining the phylogenetic relationships among the species and to determine whether species whose taxonomic positions are not clear (8) should be considered authentic Micromonospora species, we analyzed the $16 \mathrm{~S}$ rDNAs of all of the type strains of $\mathrm{Mi}$ cromonospora species and subspecies available, as well as several strains of invalid species.

\section{MATERIALS AND METHODS}

Strains investigated and culture conditions. The strains investigated in this study are listed in Table 1 . All of these strains, which are deposited in the DSMZ-German Collection of Microorganisms and Cell Cultures GmbH, were

\footnotetext{
* Corresponding author. Mailing address: DSMZ-German Collection of Microorganisms and Cell Cultures $\mathrm{GmbH}$, Mascheroder Weg 1b, 38124 Braunschweig, Germany. Phone: 49531 2616 352. Fax: 49 5312616418 . Electronic mail address: erko@gbf-braunschweig.de.
}

cultivated on medium 65 (Streptomyces medium) as described in the DSMDeutsche Sammlung von Mikroorganismen und Zellkulturen GmbH Catalogue of Strains (3).

Analysis of 16S rDNA. Genomic DNA was extracted and the 165 rDNA was amplified as described previously (13). PCR products were sequenced directly by using a Taq DyeDeoxy terminator cycle sequencing kit (Applied Biosystems, Foster City, Calif.) as recommended by the manufacturer. The sequence reaction mixtures were electrophoresed by using an Applied Biosystems model 373A DNA sequencer.

Phylogenetic analysis. The $16 \mathrm{~S}$ rDNA sequences which we determined were compared with previously described 16S rDNA sequences for members of the order Actinomycetales available from the Ribosomal Database Project (11). Similarity values were transformed into phylogenetic distance values that compensated for multiple substitutions at any given site in the sequence (7). The leastsquares distance method of De Soete (2) and the neighbor-joining and maximum-likelihood programs contained in the PHYLIP package (5) were used to construct phylogenetic dendrograms. To calculate bootstrap values, we analyzed 300 trees by using the NJFIND and NJBOOT programs.

Nucleotide sequence accession numbers. The 16S rDNA sequences which we determined have been deposited in the EMBL data library under accession numbers X92594 to X92631.

\section{RESULTS AND DISCUSSION}

We determined the almost complete 16S rDNA sequences of the type strains of 14 Micromonospora species and four subspecies, as well as Dactylosporangium thailandense DSM 43158. In addition, 19 strains representing invalidly published species, as well as a single undescribed Micromonospora strain, were included in this study (Fig. 1). The sequences which we determined were aligned with the sequences of members of the order Actinomycetales, and the phylogenetic positions of the strains were determined. All but one of the Micromonospora strains formed a phylogenetically tight cluster which occurred in the neighborhood of other members of the family $\mathrm{Mi}$ cromonosporaceae, such as Actinoplanes philippinensis, Couchioplanes caeruleus (19), Catenuloplanes japonicus (19), and Dactylosporangium thailandense (this study). As the number of previously published $16 \mathrm{~S}$ rDNA sequences of strains belonging to other genera of the family Micromonosporaceae is minute compared with the number of validly described species, we did not produce a phylogenetic tree of relatedness at this stage of our investigation as the intrafamily relationships may change significantly when more organisms are included.

The only strain that grouped outside the radiation of $\mathrm{Mi}$ cromonospora strains was strain DSM 43892 (= JCM 3105), which was invalidly described as "Micromonospora megalomi- 
TABLE 1. Organisms investigated, their source, and their 16S rDNA accession numbers

\begin{tabular}{|c|c|c|}
\hline Taxon & Strain & $\begin{array}{l}\text { Accession } \\
\text { no. }\end{array}$ \\
\hline Micromonospora aurantiaca & DSM $43813^{\mathrm{T}}$ & X92604 \\
\hline Micromonospora brunnea & DSM $43814^{T}$ & X92605 \\
\hline $\begin{array}{l}\text { Micromonospora carbonacea subsp. } \\
\text { carbonacea }\end{array}$ & DSM $43168^{\mathrm{T}}$ & X92599 \\
\hline $\begin{array}{l}\text { Micromonospora carbonacea subsp. } \\
\text { aurantiaca }\end{array}$ & $\operatorname{DSM} 43815^{T_{-}}$ & $\mathrm{X} 92606$ \\
\hline Micromonospora chalcea & DSM $43026^{T}$ & X92549 \\
\hline Micromonospora chersina & $\operatorname{DSM} 44151^{\mathbf{T}}$ & X92628 \\
\hline Micromonospora coerulea & DSM $43143^{T}$ & X92598 \\
\hline $\begin{array}{l}\text { Micromonospora echinospora subsp. } \\
\text { echinospora }\end{array}$ & DSM $43816^{\mathrm{T}}$ & $X 92607$ \\
\hline $\begin{array}{l}\text { Micromonospora echinospora subsp. } \\
\text { ferruginea }\end{array}$ & DSM $43141^{\mathrm{T}}$ & X92597 \\
\hline Micromonospora echinospora subsp. pallida & DSM $43817^{\mathrm{T}}$ & X92608 \\
\hline $\begin{array}{l}\text { Micromonospora halophytica subsp. } \\
\text { halophytica }\end{array}$ & DSM $43171^{\mathbf{T}}$ & X92601 \\
\hline Micromonospora halophytica subsp. nigra & DSM 43818 & X92609 \\
\hline Micromonospora inositola & DSM $43819^{\mathrm{T}}$ & X92610 \\
\hline Micromonospora olivasterospora & DSM $43868^{T}$ & X92613 \\
\hline Micromonospora purpurea & DSM $43036^{\mathbf{T}}$ & X92595 \\
\hline Micromonospora purpureochromogenes & DSM $43821^{\mathrm{T}}$ & $\times 92611$ \\
\hline Micromonospora rhodorangea & DSM $1039^{\mathrm{T}}$ & X92612 \\
\hline Micromonospora rosaria & DSM $803^{\mathrm{T}}$ & X92631 \\
\hline "Micromonospora brunnenscens" & DSM 43902 & X92616 \\
\hline "Micromonospora citrea" & DSM 43903 & X92617 \\
\hline "Micromonospora echinoaurantiaca" & DSM 43904 & X92618 \\
\hline "Micromonospora echinobrunnea" & DSM 43913 & X92625 \\
\hline "Micromonospora floridensis" & DSM 43907 & X92621 \\
\hline "Micromonospora fulvoviridis" & DSM 43906 & X92620 \\
\hline "Micromonospora fulvoviolacea" & DSM 43905 & X92619 \\
\hline "Micromonospora globosa" & DSM 43170 & X92600 \\
\hline "Micromonospora inyoensis" & DSM 46123 & X92629 \\
\hline "Micromonospora lacustris" & DSM 43908 & $\mathrm{X} 92622$ \\
\hline $\begin{array}{l}\text { "Micromonospora megalomicea subsp. } \\
\text { megalomicea" }\end{array}$ & DSM 43892 & X92614 \\
\hline "Micromonospora melanosporea" & DSM 43126 & $\mathrm{X} 92596$ \\
\hline "Micromonospora narashino" & DSM 43172 & X92602 \\
\hline "Micromonospora peucetica" & DSM 43363 & X92603 \\
\hline $\begin{array}{l}\text { "Micromonospora sagamiensis subsp. } \\
\text { sagamiensis" }\end{array}$ & DSM 43912 & X92624 \\
\hline "Micromonospora viridifaciens" & DSM 43909 & X92623 \\
\hline "Micromonospora yulongensis" & DSM 43915 & X92626 \\
\hline "Micromonospora fulvopurpureus" & DSM 43918 & $\mathrm{X} 92627$ \\
\hline Micromonospora sp. & DSM 43893 & X92615 \\
\hline Dactylosporangium thailandense & DSM $43158^{T}$ & X92630 \\
\hline
\end{tabular}

cea subsp. megalomicea." While the levels of similarity between strain DSM 43892 and authentic Micromonospora strains ranged from 89 to $90 \%$, the levels of similarity between strain DSM 43892 and representatives of the genus Streptomyces (21) ranged from 97 to $98.6 \%$. The relatedness of strain DSM 43892 to streptomycetes was confirmed by the presence of the diagnostic compound LL-diaminopimelic acid in whole-cell extracts and by the results of a fatty acid analysis which revealed that when the pattern for this strain was compared with the patterns available for other actinomycetes, the highest matching coefficient was with Streptomyces viridochromogenes (data not shown).

Phylogenetic relationships among the Micromonospora type strains. The levels of relatedness obtained for the type strains of the Micromonospora spp. were high, ranging from 97.2 to $99 \%$ (Table 2). The levels of similarity for many type strains of Micromonospora species were actually so high (>98.0\%) that their species status could not be confirmed on the basis of these data alone. DNA-DNA hybridization studies that could confirm the presence of genospecies that correspond to the phenotypically defined species have not been performed. However, as long as DNA-DNA reassociation values are not available, we believe that the isolated positions of the species on the phylogenetic dendrogram indicate that the species are valid.

The 16S rDNAs of the subspecies of Micromonospora carbonacea (i.e., Micromonospora carbonacea subsp. carbonacea and Micromonospora carbonacea subsp. aurantiaca) are virtually identical (level of similarity, 99.9\%). Likewise, two of the three subspecies of Micromonospora echinospora (Micromonospora echinospora subsp. echinospora and Micromonospora echinospora subsp. ferruginea) have almost identical 16S rDNA sequences (level of similarity, 99.7\%); the third subspecies, Micromonospora echinospora subsp. pallida, is more distantly related to the other two subspecies. Interestingly, the latter

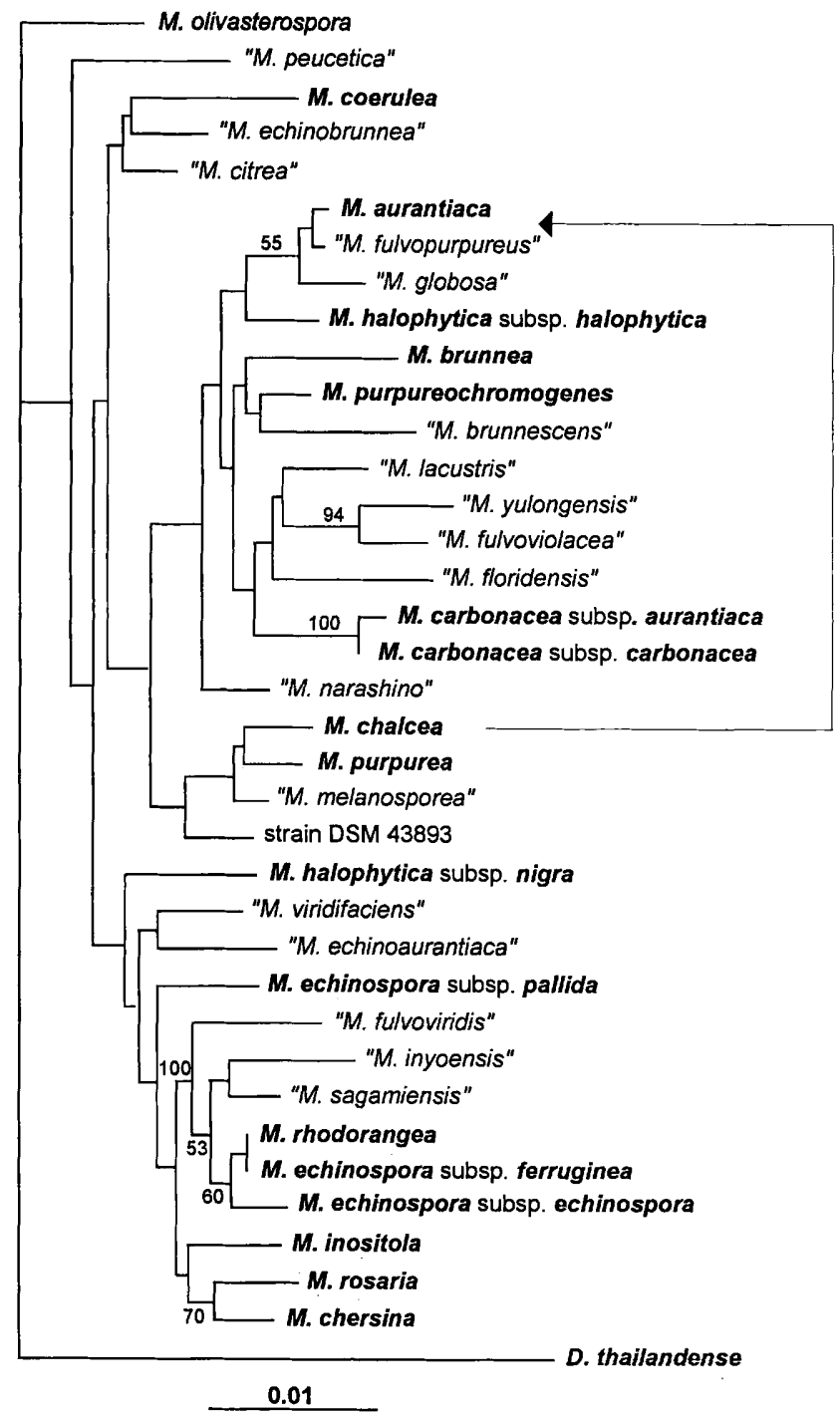

FIG. 1. Neighbor-joining dendrogram $(5,14)$ showing the phylogenetic positions of validly and invalidly described Micromonospora species and a Micromonospora strain, based on the results of an analysis of almost complete $16 \mathrm{~S}$ rDNA sequences (a similarity matrix is not shown). The arrow indicates an alternative phylogenetic position of $M$. chalcea. The numbers on the dendrogram are the percentages of occurrence in 300 bootstrapped trees; only values greater than $20 \%$ are shown. Bar $=1$ nucleotide substitution per 100 nucleotides. 
TABLE 2. Similarity matrix based on $16 \mathrm{~S}$ rDNA sequence comparisons for the type strains of Micromonospora species

\begin{tabular}{|c|c|c|c|c|c|c|c|c|c|c|c|c|c|c|c|c|c|}
\hline \multirow[b]{2}{*}{ Species or subspecies } & \multicolumn{17}{|c|}{ \% Similarity with: } \\
\hline & 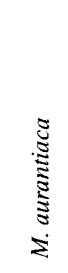 & 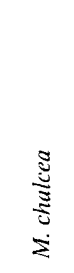 & 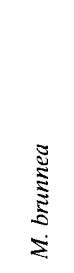 & 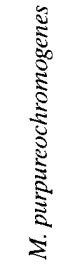 & 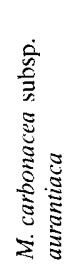 & 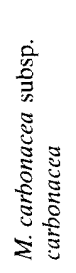 & 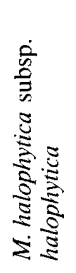 & 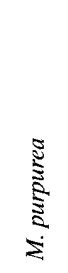 & 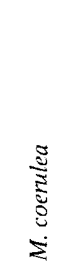 & 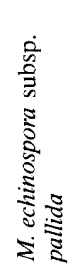 & 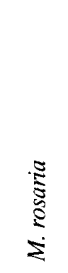 & 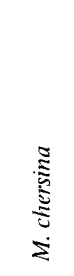 & 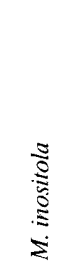 & 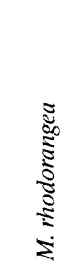 & 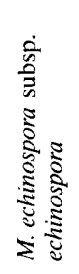 & 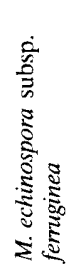 & 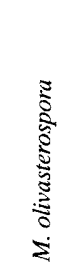 \\
\hline M. chalcea & 99.1 & & & & & & & & & & & & & & & & \\
\hline M. brunnea & 98.4 & 98.3 & & & & & & & & & & & & & & & \\
\hline M. purpureochromogenes & 99.3 & 98.5 & 98.8 & & & & & & & & & & & & & & \\
\hline M. carbonacea subsp. aurantiaca & 98.4 & 97.7 & 97.9 & 98.6 & & & & & & & & & & & & & \\
\hline M. carbonacea subsp. carbonacea & 98.5 & 97.9 & 98.0 & 98.6 & 99.9 & & & & & & & & & & & & \\
\hline M. halophytica subsp. halophytica & 99.1 & 98.7 & 98.3 & 99.0 & 98.5 & 98.6 & & & & & & & & & & & \\
\hline M. purpurea & 98.5 & 99.3 & 97.7 & 97.9 & 97.1 & 97.3 & 98.0 & & & & & & & & & & \\
\hline M. coerulea & 97.8 & 97.6 & 97.4 & 98.2 & 97.3 & 97.5 & 97.8 & 98.0 & & & & & & & & & \\
\hline M. echinospora subsp. pallida & 98.0 & 97.8 & 97.7 & 98.1 & 98.1 & 98.2 & 98.3 & 98.1 & 98.0 & & & & & & & & \\
\hline M. rosaria & 98.2 & 98.4 & 97.9 & 98.1 & 97.7 & 97.8 & 98.0 & 98.8 & 98.0 & 98.4 & & & & & & & \\
\hline M. chersina & 97.8 & 98.1 & 98.4 & 98.2 & 97.5 & 97.7 & 97.8 & 98.6 & 98.2 & 98.4 & 99.2 & & & & & & \\
\hline M. inositola & 97.8 & 97.9 & 98.0 & 98.1 & 97.9 & 97.9 & 98.1 & 98.4 & 98.0 & 98.9 & 98.7 & 99.1 & & & & & \\
\hline M. rhodorangea & 98.1 & 98.0 & 97.7 & 98.2 & 98.2 & 98.2 & 98.6 & 98.4 & 98.4 & 99.2 & 98.8 & 98.9 & 99.2 & & & & \\
\hline M. echinospora subsp. echinospora & 97.7 & 97.7 & 97.4 & 97.9 & 97.9 & 97.9 & 98.2 & 98.2 & 98.0 & 98.9 & 98.6 & 98.7 & 98.8 & 99.7 & & & \\
\hline M. echinospora subsp. ferruginea & 98.1 & 98.0 & 97.7 & 98.2 & 98.2 & 98.2 & 98.6 & 98.4 & 98.4 & 99.2 & 98.8 & 98.9 & 99.2 & 100.0 & 99.7 & & \\
\hline M. olivasterospora & 97.7 & 97.2 & 96.9 & 97.9 & 98.0 & 98.2 & 97.6 & 97.6 & 98.0 & 98.1 & 97.8 & 97.6 & 97.7 & 98.0 & 97.7 & 98.0 & \\
\hline D. thailandense & 95.2 & 95.4 & 94.8 & 95.2 & 95.4 & 95.6 & 95.6 & 95.7 & 95.4 & 95.6 & 95.8 & 95.6 & 95.8 & 96.0 & 95.8 & 96.0 & 96.3 \\
\hline
\end{tabular}

subspecies is characterized chemotaxonomically by the presence of high concentrations of menaquinones of the MK$12\left(\mathrm{H}_{4,6,8}\right)$ type $(1)$, which are not present in other Micromonospora type strains [which contain mainly menaquinones of the MK-9 $\left(\mathbf{H}_{4}, \mathrm{H}_{6}\right)$ and MK-10( $\left.\mathrm{H}_{4}, \mathrm{H}_{6}\right)$ types $\left.(1,6,10)\right]$. Apparently, the genus Micromonospora is more heterogeneous with respect to menaquinone composition than other actinomycete genera that exhibit similar high levels of intrageneric relatedness.

However, no species exhibits such a high level of 16S rDNA relatedness to another species that the two taxa could be considered synonymous or subspecies. This is also true for most of the strains belonging to taxa considered by Kawamoto (8) to be species incertae sedis. Not only are all of the species genuine members of the genus Micromonospora, but considering the isolated position of Micromonospora purpurea and Micromonospora brunnea on the tree they also do not appear to be subspecies of $M$. echinospora or subjective synonyms of $M i$ cromonospora purpureochromogenes, as proposed by Szabo and Fernandez (18). Micromonospora aurantiaca ATCC $27029^{\mathrm{T}}$ $\left(=\mathrm{DSM} 43813^{\mathrm{T}}\right)(\mathrm{T}=$ type strain), which was thought to be a member of the genus Actinoplanes because of the formation of globose or subglobose sporangia that contain spores having one polar tuft of flagella (8), is an authentic Micromonospora species. Micromonospora rhodorangea DSM 1039, the type strain of a species whose taxonomic position is uncertain, appears to be a sporeless variant (8) of $M$. echinospora subsp. ferruginea (level of 16S rDNA similarity, 100\%). To confirm that the sequence of $M$. rhodorangea DSM $1039^{\mathrm{T}}$ is identical to that of $M$. rhodorangea DSM $43822^{\mathrm{T}}$, we analyzed a stretch of 500 nucleotides of the $16 \mathrm{~S}$ rDNA of the latter strain (there are two Deutsche Sammlung von Mikroorganismen und Zellkulturen $\mathrm{GmbH}$ numbers for the same type strain because the same strain was obtained independently from two different partial Deutsche Sammlung von Mikroorganismen und Zellkulturen $\mathrm{GmbH}$ collections prior to the unification of the
West and East German collections). As the sequences of the stretches of the two type strains of $M$. rhodorangea were identical, the authenticity of this species was confirmed. Whether $M$. rhodorangea should be transferred to $M$. echinospora should be decided after a thorough comparative analysis of physiological and chemotaxonomic characteristics and DNA pairing experiments are performed.

When the 16S rDNA sequence of $D$. thailandense was used to root the phylogenetic dendrograms, Micromonospora olivasterospora was the deepest rooting species, followed by $\mathrm{Mi}$ cromonospora coerulea. The remaining species formed three subclusters, whose species compositions were the same with all of the treeing programs which we used. Subcluster I contains $M$. aurantiaca, $M$. purpureochromogenes, M. brunnea, Micromonospora halophytica, and $M$. carbonacea. Subcluster II contains the type species of the genus, $M$. chalcea, and $M$. purpurea, while subcluster III contains $M$. echinospora, $M$. rhodorangea, Micromonospora inositola, Micromonospora rosaria, and Micromonospora chersina. A representative tree based on neighbor-joining method results is shown in Fig. 2. While some of the internal relationships were confirmed by bootstrap values greater than $50 \%$, the branching order of the subclusters remains unresolved. The bootstrap values for the branch points that separate the subclusters are low and thus reveal no confidence in branch topology. However, the species compositions of subclusters I and III are supported by the presence of certain signature nucleotides between 16S rDNA positions 603 and 627 (Table 3). The relationship between the two subcluster II species, $M$. chalcea and $M$. purpurea, is a moot point. As judged from the distribution of the signature nucleotides (Table 3 ), $M$. chalcea could be considered a member of subcluster I, while $M$. purpurea is a member of subcluster III. Indeed, bootstrap values of $37 \%$ support to some extent clustering $M$. chalcea with $M$. aurantiaca, while the bootstrap value for the $M$. chalcea-M. purpureus pair is as low as $20 \%$. A possible alternative relationship of $M$. chalcea to members of subcluster 


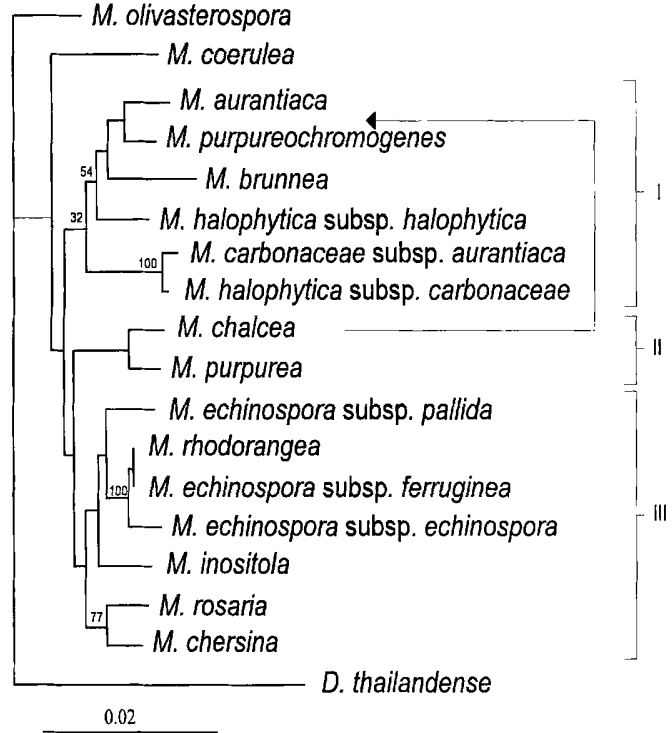

FIG. 2. Neighbor-joining dendrogram $(5,14)$ showing the intrageneric relationships of Micromonospora type strains, based on the results of an analysis of almost complete $16 \mathrm{~S}$ rDNA sequences. The similarity values are shown in Table 2. The numbers on the dendrogram are the percentages of occurrence in 300 bootstrapped trees; only values greater than $20 \%$ are shown. $\mathrm{Bar}=2$ nucleotide substitutions per 100 nucleotides. The arrow indicates an alternative phylogenetic position of $M$. chalcea.

I is indicated in Fig. 2. The two species that group outside the three subclusters ( $M$. olivasterospora and $M$. coerulea) have the subcluster III signature nucleotides, which can therefore be considered the $16 \mathrm{~S}$ rDNA nucleotides found in the common ancestor of the genus.

Phylogenetic positions of other Micromonospora strains and invalid Micromonospora species. The inclusion of 19 other $\mathrm{Mi}$ cromonospora strains, most of which are members of invalidly described species, did not change the phylogenetic relationships significantly (Fig. 1) (similarity values not shown) when neighbor-joining or maximum-likelihood programs were used to generate dendrograms. The clear distinctions among the three subclusters, however, were blurred by the branch points of the additional strains. On the other hand, the members of subclusters I and III contain the $16 \mathrm{~S}$ rDNA signature nucleotides of their subclusters. $M$. coerulea, which appears to be isolated in Fig. 2, groups with "Micromonospora citrea" DSM 43903 and "Micromonospora echinobrunnea" DSM 43913. "Micromonospora peucetica" DSM 43363 represents another deep

TABLE 3. Distribution of 16S rDNA signature nucleotides in members of Micromonospora subclusters

\begin{tabular}{lcccc}
\hline \multirow{2}{*}{$\begin{array}{l}\text { Nucleotide } \\
\text { positions in } \\
\text { 16S rDNA }\end{array}$} & Subcluster I & \multicolumn{3}{c}{ Base pair in: } \\
\cline { 2 - 4 } & & Subcluster II & \multirow{2}{*}{ Subcluster III $^{a}$} \\
\cline { 2 - 4 } & C-G & C-G & U-A & U-A \\
\hline $603-635$ & U-A & C-G & C-G & C-G \\
$612-628$ & U-A & U-A & C-G & C-G \\
$613-627$ & G-C & G-C & C-G & C-G \\
$615-625$ & G-C & G-C & A-U & A-U $(G-U)^{b}$ \\
$616-624$ & &
\end{tabular}

${ }^{a}$ These base pairs are also found in $M$. olivasterospora and in $M$. coerulea and related strains.

' The base pair in parentheses occurs in M. echinospora subsp. pallida. rooting lineage and contains the subcluster III signature nucleotides.

The only deviation in the branching patterns was observed when the least-squares distance method of De Soete (2) was applied to the full data set. While the neighbor-joining and maximum-likelihood programs clustered $M$. chalcea and $M$. purpurea together with "Micromonospora melanosporea" DSM 43126 and strain DSM 43893, the least-squares method separated $M$. chalcea from the other subcluster II strains and placed this organism between $M$. aurantiaca and Micromonospora halophytica subsp. halophytica. M. purpurea and strains DSM 43893 and DSM 43126 remained in an intermediate position as members of an individual branch between subclusters I and III. As indicated above, this grouping of $M$. chalcea within the radiation of members of subcluster I is consistent with the presence of a higher number of common signature nucleotides (Table 3). A bootstrap value of $77 \%$ supports the grouping of M. purpurea and "M. melanosporea," while the values found for these two organisms and $M$. chalcea are not significant. The alternative position of $M$. chalcea is indicated in Fig. 1.

Most of the undescribed Micromonospora strains appear to be unrelated to each other, and their relationships resemble the relationships among the valid species. This is also true for the two subspecies of $M$. halophytica, $M$. halophytica subsp. halophytica and Micromonospora halophytica subsp. nigra, which belong to subclusters I and III, respectively. This may be an indication that $M$. halophytica subsp. nigra, $M$. echinospora subsp. pallida, and each of the invalidly described species actually do represent a new species. As mentioned above, according to the recommendations for descriptions of species (20), any decision concerning taxonomic status should be made only after extensive DNA-DNA hybridization experiments are performed. Considering the similar, sometimes almost identical, 16S rDNA sequences of strains belonging to different species and the few distinguishing phenotypic properties, DNA pairing experiments (15) may show that the genus Micromonospora is overclassified and different species may have to be combined.

\section{REFERENCES}

1. Collins, M. D., M. Faulkner, and R. M. Keddie. 1984. Menaquinone composition of some sporeforming actinomycetes. Syst. Appl. Microbiol. 5:2029.

2. De Soete, G. 1983. A least squares algorithm for fitting additive trees to proximity data. Psychometrica 48:621-626.

3. DSM-Deutsche Sammlung von Mikroorganismen und Zellkulturen GmbH. 1993. Catalogue of strains, 5th ed. DSM-Deutsche Sammiung von Mikroorganismen und Zellkulturen GmbH, Braunschweig, Germany.

4. Embley, T. M., and E. Stackebrandt. 1994. The molecular phylogeny and systematics of the actinomycetes. Annu. Rev. Microbiol. 48:257-289.

5. Felsenstein J. 1993. PHYLIP (phylogeny inference package), version 3.5c. University of Washington, Seattle.

6. Goodfellow, M., L. J. Stanton, K. E. Simpson, and D. E. Minnikin. 1990. Numerical and chemical classification of Actinoplanes and some related actinomycetes. J. Gen. Microbiol. 136:19-36.

7. Jukes, T. H., and C. R. Cantor. 1969. Evolution of protein molecules, p. 21-132. In H. N. Munro (ed.), Mammalian protein metabolism. Academic Press, New York.

8. Kawamoto, I. 1989. Genus Micromonospora Ørskov 1923, p. 2442-2450. In S. T. Williams, M. E. Sharpe, and J. G. Holt (ed.), Bergey's manual of systematic bacteriology, vol. 4. The Williams and Wilkins Co., Baltimore.

9. Krasil'nikov, N. A. 1938. Ray fungi and related organisms-Actinomycetales. Akademia Nauk SSSR, Moscow.

10. Kroppenstedt, R. M. 1987. Chemische Untersuchungen an Actinomycetales und verwandten Taxa, Korrelation von Chemosystematik und Phylogenie. Habilitation thesis. Technical University of Darmstadt, Darmstadt, Germany.

11. Larsen, N., G. J. Olsen, B. L. Maidak, M. McCaughey, J. R. Overbeek, T. J. Macke, T. L. Marsh, and C. R. Woese. 1993. The Ribosomal Database Project. Nucleic Acids Res. 21:3021-3023.

12. Ørskov, J. 1923. Investigations into the morphology of the ray fungi. Levin and Munksgaard, Copenhagen.

13. Rainey, F. A., M. Dorsch, H. W. Morgan, and E. Stackebrandt. 1992. 16S 
rDNA analysis of Spirochaeta thermophila: its phylogenetic position and implications for the systematics of the order Spirochaetales. Syst. Appl. Microbiol. 15:197-202.

14. Saitou, N., and M. Nei. 1987. The neighbor-joining method: a new method for reconstructing phylogenetic trees. Mol. Biol. Evol, 4:406-425.

14a.Skerman, V. D. B., V. McGowan, and P. H. A. Sneath (ed.). 1980. Approved lists of bacterial names. Int. J. Syst. Bacteriol. 30:225-420.

15. Stackebrandt, E., and B. M. Goebel. 1994. A place for DNA-DNA reassociation and $16 \mathrm{~S}$ rRNA sequence analysis in the present species definition in bacteriology. Int. J. Syst. Bacteriol. 44:846-849.

16. Stackebrandt, E., W. Ludwig, E. Seewaldt, and K. H. Schleifer. 1983. Phylogeny of spore-forming members of the order Actinomycetales. Int. J. Syst. Bacteriol. 33:173-180.

17. Stackebrandt, E., and C. R. Woese. 1981. Towards a phylogeny of actinomycetes and related organisms. Curr. Microbiol. 5:131-136.

18. Szabo, Z., and C. Fernandez. 1984. Micromonospora brunnea Sveshnikova, Maksimova, and Kudrina 1969 is a junior subjective synonym of Micromonospora purpureochromogenes (Waksman and Curtis 1916) Luedemann 1971.
Int. J. Syst. Bacteriol. 34:463-464.

19. Tamura, T., Y. Nakagaito, T. Nishii, T. Hasegawa, E. Stackebrandt, and A. Yokota. 1994. A new genus of the order Actinomycetales, Couchioplanes gen. nov., with description of Couchioplanes caeruleus (Horan and Brodsky 1986) comb. nov. and Couchioplanes caeruleus subsp. azureus subsp. nov. Int. J. Syst. Bacteriol. 44:193-203.

20. Wayne, L. G., D. J. Brenner, R. R. Colwell, P. A. D. Grimont, O. Kandler, M. I. Krichevsky, L. H. Moore, W. E. C. Moore, R. G. E. Murray, E. Stackebrandt, M. P. Starr, and H. G. Trüper. 1987. Report of the Ad Hoc Committee on Reconciliation of Approaches to Bacterial Systematics. Int. J. Syst. Bacteriol. 37:463-464.

21. Witt, D., and E. Stackebrandt. 1990. Phylogenetic and phenotypic similarities between members of the genera Streptomyces and Streptoverticillium support the unification of the two genera. Syst. Appl. Microbiol. 13:361-371.

22. Yokota, A., T. Tamura, T. Hasegawa, and L. H. Huang. 1993. A new genus of the order Actinomycetales: Catenuloplanes japonicus gen. nov., sp. nov. Int. J. Syst. Bacteriol. 43:805-812. 